\author{
Д.Н. Баринов
}

\title{
ВОЗДЕЙСТВИЕ МЕДИАНОВОСТЕЙ НА ЭМОЦИОНАЛЬНОЕ САМОЧУВСТВИЕ РЕГИОНАЛЬНОЙ АУДИТОРИИ СМИ
}

\begin{abstract}
Аннотация. В статье представлены результаты эмпирического исследования влияния медиановостей на эмоииональное самочувствие региональной аудитории СМИ. Новости СМИ нередко драматизируют происходящее в реальности, усиливают необычный и анормальный характер того или иного события, что способствует возникновению негативных эмоциональных состояний, в том числе страха и тревоги. В этой связи исследование эмоционального фона восприятия новостей было ориентировано на выявление особенностей возникновения страха и тревоги под влиянием новостей СМИ. Инструментарий разрабатывался на основе методик, апробированных в современных медиаисследованиях. Теоретической основой исследования послужили научные работы в области социологии массовой коммуникации и социологического изучения социальных страхов. Сформулированы следующие выводы. Помимо вовлечённости региональной аудитории СМИ в прочесс потребления медиановостей, на характер эмоциональных переживаний оказывают влияние социально-демографические факторы. Повидимому, представители социальных групп экстраполируют культурные правила выражения эмоций, убеждения, оценки, установки, обусловленные их положением в системе общественных отношений на новостные материалы, что усиливает или снижает воздействие страхогенной информации. Наиболее уязвимыми к страхогенной информации новостей СМИ являются социальные группы, положение которых в системе общественных отношений можно охарактеризовать как неустойчивое, неопределённое или не в полной мере защищённое. Ключевые слова: сочиология массовых коммуникаций, аудитория СМИ, новости СМИ, повестка дня, социальные страхи, эмоциональное самочувствие, общественные настроения, психология масс, массово-информационное воздействие, медиапрактики.

Abstract. The article presents the results of the empirical research studying the influence of medianews on the emotional well-being of media audience in regions. Quite often mass media dramatizes real events and aggravates unusual or abnormal nature of this or that event, thus creating negative emotional states such as anxiety or fear. With that in mind, Barinov aims his research of the emotional effect of news at defining peculiar conditions when anxiety and fear arise as a result of watching or listening to media news. The instruments used in the course of the research are based on the methods tested and proved by modern media researches. The theoretical basis of the research consists of scientific publications in teh sphere of sociology of mass communication and sociological research of social fears. The followoing conclusions have been made. Besides the factor of involving regions' audience into the process of medianews consumption, the nature of emotional states are also influenced by sociodemographic factors. Apparently, representatives of social groups extrapolate rules of cultural behavior regarding expressing emotions, values, attitudes and evaluations on news which either intensifies or weakens the role of such information in generation of fears and anxiety. Social groups whose positions within social relations can be described as unstable, insecure or uncertain are especially vulnerable and susceptible to fear-generating mass media information.
\end{abstract}

Key words: mass media influence, public mood, mass psychology, emotional well-being, social fears, agenda-setting, news media, media audience, sociology of mass communications, media practice.

\section{Актуальность исследования и описание методики}

Неотъемлемой частью современного общества является медиасфера, степень воздействия которой на повседневную жизнь человека и общественные настроения не меньшая, чем от реальных социаль- ных процессов. В современном обществе отношение к тем или иными аспектам общественной жизни, ментальные модели реальности и социальные практики во многом определяются медиадискурсом. Среди продуктов СМИ популярными и влиятельными являются новости. В мае 2014 г. новости СМИ заняли лидирующие позиции в рейтинге 
телевизионных предпочтений россиян (72\%) [11].

К числу существенных признаков новостей СМИ исследователи относят новизну, драматизацию отображаемых событий, отклонение от нормы $[1 ; 4 ; 6$; 9]. Построенные в соответствии с этими признаками новости СМИ способны возбуждать негативные эмоциональные состояния, создавать неблагоприятный эмоциональный фон, который может стать преобладающим в общественных настроениях.

С целью изучения воздействия медиановостей на эмоциональное самочувствие региональной аудитории СМИ в мае 2014 г. в г. Смоленске был проведён социологический опрос. Объём выборки составил 400 человек. Репрезентативность обеспечивалась соблюдением параметров выборки по полу и возрасту. Инструментарий разработан на основе методик, принятых в современных практиках медиаисследований. Анкета включала два блока вопросов. Первый блок нацелен на исследование особенностей потребления новостного контента региональной аудиторией СМИ. Второй блок вопросов анкеты обращён к изучению эмоционального фона восприятия новостей СМИ. Поскольку, как отмечалось, новости зачастую драматизируют происходящее в реальности, усиливают акценты, подчёркивающие незаурядный и анормальный характер того или иного события, исследование эмоционального фона восприятия новостей было ориентировано на установление особенностей возникновения страха и тревоги под влиянием новостей СМИ.

\section{Практики потребления новостей СМИ}

Несмотря на то, что в последние годы заметно возросло количество пользователей персональных компьютеров и Интернета [5; 7], наиболее популярным источником новостной информации у жителей г. Смоленска остаётся телевидение. Его указало подавляющее большинство респондентов (табл. 1).

Таблица 1*.

\begin{tabular}{|c|c|}
\hline \multicolumn{2}{|c|}{$\begin{array}{c}\text { Из каких источников лично Вы чаще всего } \\
\text { получаете новости, информацию о события } \\
\text { в России и мире? } \\
\text { N=400, май } 2014 \text { г., в } \% \\
\end{array}$} \\
\hline \multicolumn{2}{|c|}{ Варианты } \\
\hline Телевидение & 89 \\
\hline Интернет & 49 \\
\hline Родственники, близкие люди & 31 \\
\hline Печатные СМИ (газеты, журналы) & 27 \\
\hline Коллеги по работе, знакомые & 27 \\
\hline Радио & 23 \\
\hline Другое & 1 \\
\hline Затрудняюсь ответить & 0,5 \\
\hline
\end{tabular}

* Сумма по столбцу более $100 \%$, т.к. респондентам предлагалось выбрать несколько вариантов ответов
Это отвечает тенденциям развития медисферы в условиях дигитализации СМИ. Рост телесмотрения, расширение телевизионного контента и перечня каналов позволяют современному телевидению сохранять лидирующие позиции [3, с. 97-98].

Предпочтения выбора того или иного канала новостной информации определяются социально-демографическими характеристиками региональной аудитории СМИ. Так, наиболее активно используют Интернет в качестве источника новостей респонденты в возрасте до 45 лет (18-24 года - 68\%, 25-34 года - 78\%, 35-44 года - 67\%). В группах старше 45 лет, число получающих новости из Интернета, заметно ниже (45-54 года - 45\%, 55-64 года - 19\%). А среди жителей города в возрасте 65 лет и старше таких 7\%. Это соответствует современной структуре российской интернет-аудитории: наиболее высокая активность в Интернете свойственна пользователям в возрасте от 19 до 23 лет, наименьшая - пользователям в возрасте старше 64 лет [2, с. 9].

Возраст респондентов выступает фактором, определяющим частоту получения новостей СМИ и планирование обращения к новостям. Последнее можно считать индикатором устойчивости интереса к новостной информации СМИ. Наиболее активными получателями новостей («несколько раз в день или не менее одного раза в день») являются смоляне в возрасте 65 лет и старше (90\%). Среди представителей молодого поколения смолян в возрасте 1824 года таких почти в два раза меньше - 53\%. Также с возрастом увеличивается число тех, кто ответил, что заранее готовится к получению новостей СМИ. Если среди молодёжи (18-24 года) доля таких респондентов составила $4 \%$, то среди представителей старшего возраста (65 лет и старше) - 28\%.

Важную роль в эмоциональном самочувствии аудитории СМИ играет повестка дня, фокусирующая внимание на наиболее актуальных проблемах и определяющая круг новостей, вызывающих эмоциональный отклик у аудитории. Преобладающими темами в новостях СМИ, по мнению представителей региональной аудитории, являются: политика, деятельность органов государственной власти и криминальные новости (по 74\%). Следующую строчку занимают аварии, катастрофы (70\%). Другие тематические разделы новостей отметили менее половины респондентов (табл. 2).

Тематический рейтинг лидирующих новостей, бесспорно, отражает повестку дня СМИ, которая представляет актуальную на данный момент («здесь-и-сейчас») новостную проблематику. Поэтому лидирующие позиции занимают новости о политике, которые, как правило, первыми освещаются в выпусках новостных передач. 


\section{Психология и психотехника 7(94) • 2016}

Таблица 2*.

\begin{tabular}{|l|c|}
\hline \multicolumn{1}{|c|}{$\begin{array}{c}\text { Какие темы чаще всего встречаются в новостях } \\
\text { средств массовой информации? } \\
\text { N=400, май 2014 г., в \% }\end{array}$} \\
\hline \multicolumn{1}{|c|}{ Варианты } \\
\hline $\begin{array}{l}\text { Политика, деятельность российских органов государ- } \\
\text { ственной и политической власти }\end{array}$ & 74 \\
\hline Криминал, скандалы, происшествия & 74 \\
\hline Аварии, катастрофы & 70 \\
\hline Международные политические события & 48 \\
\hline Экономика, финансы & 44 \\
\hline Спорт & 31 \\
\hline Светские новости, жизнь известных, знаменитых людей & 20 \\
\hline Культура, искусство, кино & 14 \\
\hline Медицина & 13 \\
\hline Наука, образование & 12 \\
\hline Технологии, технические достижения & 7 \\
\hline Промышленное производство, сельское хозяйство & 6 \\
\hline Компьютеры и компьютерные технологии & 5 \\
\hline Затрудняюсь ответить & 2 \\
\hline Другое & 0,3 \\
\hline \hline
\end{tabular}

* Сумма по столбцу более $100 \%$, т.к. респондентам предлагалось выбрать несколько вариантов ответов

Показательно, что в число главенствующих тем новостей попали так называемые чрезвычайные новости (криминал, аварии и т.п.), способные оказывать дестабилизирующее воздействие на эмоциональное состояние и настроения аудитории, провоцировать страх и тревогу [1; 13; 14; 15]. Отмеченная тенденция характерна не только для региональной аудитории СМИ, но и для общенациональной. В общероссийских исследованиях, проведённых летом 2014 г., лидирующими новостями по критерию запоминаемости являются новости катастрофического формата [8].

\section{Эмоциональный фон восприятия новостей СМИ}

В качестве одного из показателей эмоционального отношения региональной аудитории к новостям СМИ можно рассматривать оценку новостных сообщений как оптимистических или пессимистических. Почти половина опрошенных смолян (48\%) убеждена в том, что в новостях СМИ доминирует пессимистическая информация $37 \%$ - скорее, пессимистическая, $11 \%$ - безусловно, пессимистическая). Каждый пятый респондент (20\%) (3\% - безусловно, оптимистическая, $17 \%$ - скорее, оптимистическая) характеризовал новостную информацию как оптимистическую. 23\% отметили, что пессимистической и оптимистической информации в новостных сообщениях поровну. Совсем незначительна (5\%) доля тех, кто уверен, что в новостях встречается преимущественно нейтральная информация. $4 \%$ затруднились ответить.
В ходе опроса определялось отношение представителей региональной аудитории СМИ к новостной репрезентации реалий российской жизни с точки зрения безопасности («Если оценивать по новостям средств массовой информации, жизнь большинства людей в современной России стала опасней или безопасней?»). Как выяснилось, новости рисуют такую картину социальной реальности, которая половиной респондентов (54\%) рассматривается как небезопасная $(20 \%$ - безусловно, опасней и $34 \%$ - скорее опасней). В два раза меньше (27\%) респондентов уверены в том, что, судя по новостям СМИ, жизнь в России стала безопасней ( $22 \%$ - скорее безопасной и $5 \%$ - безусловно, безопасной). $19 \%$ опрошенных затруднились ответить.

Рассматривать представленную в новостях СМИ реальность российской жизни как опасную чаще склонны женщины (58\%) и респонденты с высшим образованием (61\%).

Какие же чувства, эмоции чаще всего возникают у региональной аудитории СМИ после просмотра (чтения, прослушивания) новостей СМИ? Согласно полученным в ходе опроса данным, жители г. Смоленска в числе эмоциональных переживаний называли: тревогу - 42\%, возмущение - $39 \%$, раздражение - $32 \%$, разочарование - $28 \%$, стыд $-18 \%$, неуверенность - 17\%. Затруднились определить своё эмоциональное состояние 6,0\% (табл. 3).

Таблица 3*.

\begin{tabular}{|c|c|c|c|}
\hline \multicolumn{4}{|c|}{$\begin{array}{c}\text { Какие чувства, эмоции чаще всего возникают у } \\
\text { Вас при получении из средств массовой инфор- } \\
\text { мации новостей о событиях в стране и мире? } \\
\text { N=400, май } 2014 \text { г., в \% }\end{array}$} \\
\hline \multicolumn{4}{|c|}{ Варианты } \\
\hline \multicolumn{2}{|c|}{ Отрицательные эмоции } & \multicolumn{2}{|c|}{ Положительные эмоции } \\
\hline Тревога & 42 & Удивление & 34 \\
\hline Возмущение & 39 & Надежда & 18 \\
\hline Раздражение & 32 & Радость & 5 \\
\hline Разочарование & 28 & Удовлетворённость & 5 \\
\hline Стыд & 18 & Доверие & 5 \\
\hline Неуверенность & 17 & Гордость & 5 \\
\hline Страх & 13 & Спокойствие & 4 \\
\hline Отвращение & 11 & Уверенность & 4 \\
\hline Беспомощность & 9 & Защищённость & 3 \\
\hline Беззащитность & 9 & Другое & 2 \\
\hline Обида & 7 & Уверенность & 1 \\
\hline
\end{tabular}

* Сумма более $100 \%$, т.к. респондентам предлагалось выбрать несколько вариантов ответов

Женщины чаще мужчин называли такие эмоции, как тревога (45\%), возмущение $(44 \%)$, беззащитность (14\%), беспомощность (13\%), обида (9\%). У мужчин после обращения к новостям возникают стыд (23\%), неуверенность (20\%), отвращение (12\%).

Во всех социально-демографических группах региональной аудитории СМИ преобладающим 


\section{Психология масс}

эмоциональным переживанием, которое возникало после обращения к медиановостям, является тревога. Её упомянули не менее $40 \%$ респондентов в различных группах. Исключение составляет молодёжь (18-24 года). Половина представителей молодого поколения (51\%) в качестве эмоционального переживания, возникающего после знакомства с новостями СМИ, назвала удивление. Очевидно, что возраст предопределяет направленность интереса к определённым тематическим группам новостей. В случае с молодёжью речь, вероятно, должна идти о новостной информации развлекательного характера. Это и сказывается на эмоциональном самочувствии молодёжной аудитории СМИ областного центра.

Репертуар эмоций, выявленный в ходе проведения опроса, коррелирует с результатами исследований прошлых лет. Согласно данным, полученным в 1994 г., среди негативных чувств, переживаемых респондентами при просмотре информационных телевизионных передач, преобладали тревога $(59,6 \%)$ и усталость $(57,9 \%)$, среди позитивных надежда $(24,3 \%)$ и интерес $(44,7 \%)[10$, с. 31]. Это свидетельствует о единстве манеры подачи новостей, обусловленной их жанровыми особенностями, а также об устойчивом характере воздействия содержания новостного материала на эмоциональное самочувствие аудитории СМИ.

Поскольку некоторым типам новостей СМИ свойственна страхогенная составляющая, респондентам был задан следующий вопрос: «После знакомства с новостями средств массовой информации за последнюю неделю у Вас лично возникали или не возникали неуверенность в завтрашнем дне, страх за Ваше будущее, и если да, то в какой степени?». Среди смолян незначительна доля тех, кто заявил, что после знакомства с новостями СМИ они не испытывают страха, полностью уверены в завтрашнем дне (17\%). Более трети опрошенных (37\%) испытывали незначительный страх и некоторую неуверенность в завтрашнем дне. А каждый десятый (11\%) сообщил о переживании сильного страха и полной неуверенности в завтрашнем дне. 35\% затруднились ответить.

Женщины почти в три раза чаще мужчин (16\% и $6 \%$ соответственно) говорили о страхе и неуверенности после знакомства с новостями СМИ. При этом вдвое больше мужчин (23\%), чем женщин (11\%), заявили, что не испытывали страха после получения новостей. Гендерные различия в переживаниях страха и неуверенности связаны с ценностно-нормативными аспектами выражения эмоций, правилами проявления и вербализации страха в патриархальной культуре. Как полагают В.Н. Шубкин и В.А. Иванова, мужчины в меньшей степени склонны демонстрировать свои страхи, что связано с действием культурных норм, предписывающих мужчинам быть мужественными и смелыми [12, с. 133].

Следует также отметить, что на эмоциональном самочувствии региональной аудитории СМИ отражается частота получения содержащейся в медиановостях страхогенной информации. Чаще переживали страх и неуверенность в завтрашнем дне те, кто обращается к новостям ежедневно или несколько раз в день, чем те, кто получает новости СМИ несколько раз в неделю (14\% и 3\% соответственно).

\section{Заключение}

На тематический рейтинг медиановостей оказывает влияние степень их катастрофичности, способной оказывать дестабилизирующее воздействие на эмоциональное состояние и настроения аудитории СМИ, провоцировать возникновение негативных эмоциональных переживаний, в том числе страха и тревоги. Помимо вовлечённости региональной аудитории СМИ в процесс потребления медиановостей, на характер эмоциональных переживаний оказывают влияние социально-демографические факторы. По-видимому, представители социальных групп экстраполируют культурные правила выражения эмоций, убеждения, оценки, установки, обусловленные их положением в системе общественных отношений на новостные материалы, что усиливает или снижает воздействие страхогенной информации. Наиболее уязвимыми к страхогенной информации новостей СМИ являются социальные группы, положение которых в системе общественных отношений можно охарактеризовать как неустойчивое, неопределённое или не в полной мере защищённое.

\section{Список литературы:}

1. Брайант Дж., Томпсон С. Основы воздействия СМИ / Пер. с англ. М.: Изд. дом «Вильяме», 2004. 432 с.

2. Бродовская Е.В., Шумилова О.Е. Российские пользователи и непользователи: соотношение и основные особенности // Мониторинг общественного мнения: экономические и социальные перемены. 2013. № 3 (115). С. 5-18.

3. Бузин В.Н. Возможен ли закат телевидения? Социологический прогноз // Социологические исследования. 2012. № 10. С. 97-98.

4. Бурдьё П. О телевидении и журналистике / Пер. с фр. Т. Анисимовой, Ю. Марковой. Отв. ред., предисл. Н. Шматко. М.: Фонд научных исследований «Прагматика культуры», Институт экспериментальной социологии, 2002. 159 с. 


\section{Психология и психотехника 7(94) • 2016}

5. Интернет в России: динамика проникновения. Зима 2015-2016. URL: http://fom.ru/SMI-i-internet/12610.

6. Почепцов Г.Г. Теория коммуникации. М.: Рефл-бук; Киев: Ваклер, 2002. 656 с.

7. Российский статистический ежегодник. 2015: Сб. ст. / Росстат. М., 2015. 727 с.

8. Самые запоминающиеся события. Пресс-выпуск. 06.08.2014. URL: http://www.levada.ru/06-08-2014/samyezapominayushchiesya-sobytiya.

9. Х Харрис Р. Психология массовых коммуникаций. СПб.: Прайм-ЕВРОЗНАК, 2003. 448 с.

10. Хлопьев А.Т. Кривые толки России // Социологические исследования. 1995. № 1. С. 21-33.

11. Что и зачем смотрят россияне. URL: http://fom.ru/SMI-i-internet/11536.

12. Шубкин В.Н., Иванова В.А. Страх на постсоветском пространстве: Украина и Литва // Страхи и тревоги россиян. СПб.: РХГИ, 2004. С. 139-169.

13. David L. AltheideMoral panic: From sociological concept to public discourse // Crime, media, culture. 2009. № 5. P. 79-96. URL: http://cmc.sagepub.com/cgi/content/abstract/5/1/79. DOI: 10.1177/1741659008102063.

14. Jan Van den Bulck, Kathleen Custers Television exposure is related to fear of avian flu, an Ecological Study across 23 member states of the European Union // European Journal of Public Health. 2009. Vol. 19. № 4. P. 370-374. D0I:10.1093/eurpub/ ckp061.

15. Ronald Weitzer; Charis E Kubrin Breaking news: how local tv news and real-world conditions affect fear of // Justice Quarterly. 2004. Vol. 21. № 3. P. 497-520.

16. Розин В.М. Коммуникация и социальность // Политика и общество. 2014. № 9. C. 1042-1054. DOI: 10.7256/18128696.2014.9.13154.

\section{References (transliterated):}

1. Braiant Dzh., Tompson S. Osnovy vozdeistviya SMI / Per. s angl. M.: Izd. dom «Vil'yame», 2004. 432 s.

2. Brodovskaya E.V., Shumilova O.E. Rossiiskie pol'zovateli i nepol'zovateli: sootnoshenie i osnovnye osobennosti // Monitoring obshchestvennogo mneniya: ekonomicheskie i sotsial'nye peremeny. 2013. № 3 (115). S. 5-18.

3. Buzin V.N. Vozmozhen li zakat televideniya? Sotsiologicheskii prognoz // Sotsiologicheskie issledovaniya. 2012. № 10. S. 97-98.

4. Burd'e P. 0 televidenii i zhurnalistike / Per. s fr. T. Anisimovoi, Yu. Markovoi. Otv. red., predisl. N. Shmatko. M.: Fond nauchnykh issledovanii «Pragmatika kul'tury», Institut eksperimental'noi sotsiologii, 2002.159 s.

5. Internet v Rossii: dinamika proniknoveniya. Zima 2015-2016. URL: http://fom.ru/SMI-i-internet/12610.

6. Pocheptsov G.G. Teoriya kommunikatsii. M.: Refl-buk; Kiev: Vakler, 2002. 656 s.

7. $\quad$ Rossiiskii statisticheskii ezhegodnik. 2015: Sb. stat. / Rosstat. M., 2015. 727 s.

8. Samye zapominayushchiesya sobytiya. Press-vypusk. 06.08.2014. URL: http://www.levada.ru/06-08-2014/samyezapominayushchiesya-sobytiya.

9. Kharris R. Psikhologiya massovykh kommunikatsii. SPb.: Praim-EVROZNAK, 2003. $448 \mathrm{~s}$

10. Khlop'ev A.T. Krivye tolki Rossii // Sotsiologicheskie issledovaniya. 1995. № 1. S. 21-33.

11. Chto i zachem smotryat rossiyane. URL: http://fom.ru/SMI-i-internet/11536.

12. Shubkin V.N., Ivanova V.A. Strakh na postsovetskom prostranstve: Ukraina i Litva // Strakhi i trevogi rossiyan. SPb.: RKhGI, 2004. S. 139-169.

13. David L. AltheideMoral panic: From sociological concept to public discourse // Crime, media, culture. 2009. № 5. P. 79-96. URL: http://cmc.sagepub.com/cgi/content/abstract/5/1/79. DOI: 10.1177/1741659008102063.

14. Jan Van den Bulck, Kathleen Custers Television exposure is related to fear of avian flu, an Ecological Study across 23 member states of the European Union // European Journal of Public Health. 2009. Vol. 19. № 4. P. 370-374. D0I:10.1093/eurpub/ ckp061.

15. Ronald Weitzer; Charis E Kubrin Breaking news: how local tv news and real-world conditions affect fear of // Justice Quarterly. 2004. Vol. 21. № 3. P. 497-520.

16. Rozin V.M. Kommunikatsiya i sotsial'nost' // Politika i obshchestvo. 2014. № 9. S. 1042-1054. D0I: 10.7256/18128696.2014.9.13154. 